\title{
CARACTERÍSTICAS SOCIOECONÔMICAS E FINANCEIRAS PESSOAIS: ESTUDO COMPARATIVO ENTRE AS CLASSES SOCIAIS
}

\author{
PEOPLE SOCIOECONOMIC AND FINANCIAL \\ CHARACTERISTICS: A COMPARATIVE STUDY BETWEEN \\ SOCIAL CLASSES
}

Geraldo Alemandro Leite Filho ${ }^{1}$

\begin{abstract}
Resumo: O objetivo do trabalho foi verificar se houve diferenças significativas entre as características socioeconômicas e financeiras das pessoas quando separadas por classes sociais. Julgou-se importante a compreensão das principais diferenças destas variáveis entre as classes sociais. Quanto à metodologia, a pesquisa foi descritiva com uso e análise de dados secundários da investigação "A trajetória Financeira do Brasileiro" - realizada pela AMBIMA e o Instituto Datafolha, no qual realizaram 2.653 entrevistas em todo o Brasil, abrangendo 130 municípios, durante o mês de junho de 2017. Na análise dos dados, utilizou-se estatística descritiva e teste de médias. Os principais resultados evidenciaram que a Classe A apresentou a menor média de filhos, a Classe $\mathrm{C}$ apresentou menores médias de renda, condições de trabalho mais estáveis nas Classes A e B. Concluiu-se ainda que a Classe A apresentou maior escolaridade e maior letramento financeiro, houve o maior percentual de pessoas sem dividas e de pessoas com baixo endividamento enquanto na classe $\mathrm{C}$ apresentou maior percentual de pessoas superendividadas. Concluiu-se ainda que os atributos "número de filhos, renda familiar, situação laboral, estado civil, escolaridade, uso do cartão de crédito, uso de controles financeiros pessoais e níveis de endividamento pessoal" foram estatisticamente diferentes entre as classes sociais.
\end{abstract}

${ }^{1}$ Doutor em Administração pela UFLA/MG, Professor do Departamento de Ciências Contábeis da UNIMONTES, Montes Claros - MG, Brasil. 
Palavras-Chave: Características socioeconômicas. Finanças Pessoais. Classes Sociais.

\begin{abstract}
The objective of the study was to verify if there were significant differences between the socioeconomic and financial characteristics of people when separated by social class. The research was descriptive with secondary data from a sample of 2653 respondents. It was concluded that Class A had the lowest average number of children, Class $\mathrm{C}$ had lower average family income while Class A had higher income, more stable working conditions in Classes A and B, while Class $\mathrm{C}$ had the largest number of people with informal jobs and unstable employment conditions and also the largest number of unemployed people. It was also concluded that Class A had higher education and greater financial literacy, there was the highest percentage of people without debt and people with low indebtedness, while in Class $\mathrm{C}$ it had the highest percentage of over-indebted people. It was also concluded that Class $\mathrm{C}$ had the highest percentage of people with a strong tendency not to be a consumer and the highest percentages of financial lack of control. It was also concluded that the attributes "number of children, family income, employment status, marital status, education, use of credit card, use of personal financial controls and levels of personal indebtedness" were statistically different between social classes.
\end{abstract}

Keywords: Socioeconomic characteristics. Personal finance. Social classes.

Resumen: El objetivo de este trabajo fue verificar si existían diferencias significativas entre las características socioeconómicas y financieras de las personas cuando se separan por clase social. La investigación fue descriptiva con datos secundarios de una muestra de 2653 encuestados. Se concluyó que la Clase A tenía el promedio más bajo de niños, la Clase $\mathrm{C}$ tenía un ingreso familiar promedio más bajo mientras que la Clase A tenía ingresos más altos, condiciones de trabajo más estables en las Clases A y B, mientras que la Clase $\mathrm{C}$ tenía el mayor número de personas con trabajos informales. y condiciones de empleo inestables y también el mayor número de desempleados. También se concluyó que la Clase A tenía educación superior y mayor alfabetización financiera, existía el mayor porcentaje de personas sin deudas y personas con bajo endeudamiento, mientras que en la Clase $\mathrm{C}$ tenía el mayor porcentaje de personas sobreendeudadas. También se concluyó que la Clase C tenía el mayor porcentaje de personas con fuerte tendencia a no ser consumidor y los mayores porcentajes de descontrol financiero. También se concluyó 
que los atributos "número de hijos, ingreso familiar, situación laboral, estado civil, educación, uso de tarjeta de crédito, uso de controles financieros personales y niveles de endeudamiento personal" fueron estadísticamente diferentes entre clases sociales.

Palabras clave: Características socioeconómicas. Finanzas personales. Clases sociales.

\section{Introdução}

Características socioeconômicas referem-se a aspectos sociológicos, econômicos, educativos, trabalhistas e outros que possibilitam ajudar a identificar um indivíduo em um determinado grupo socioeconômico. A prática socioeconômica está relacionada com um conjunto de variáveis subjetivas que qualificam um indivíduo ou um grupo dentro de uma hierarquia ou nivelamento social (nível socioeconômico). Neste contexto, têm-se a classe social que é um grupo constituído por pessoas com padrões culturais, políticos e econômicos semelhantes. O fator financeiro também é uma das características na definição de uma classe social, sendo formada por indivíduos que constituem um mesmo nível e poder econômico. Assim, características socioeconômicas possuem relação com as características financeiras pessoais principalmente o nível de letramento financeiro das pessoas. (POMPIAN; LONGO, 2004; KIRBY et al. 2005).

Do ponto de vista de finanças pessoais, diversos estudos relacionaram características socioeconômicas com caraterísticas financeiras pessoais.

Quanto ao fator gênero, estudos evidenciaram as mulheres como mais vulneráveis à dívidas (BERG et al., 2010) e aqueles que apontam os homens (MULLER, 2010; HUANG, KISGEN, 2013). Campara et al. (2018) estudaram a relação entre características socioeconômicas e a atitude frente ao endividamento, concluindo que os homens preocupavam-se de maneira mais efetiva com a manutenção de uma boa atitude financeira, evitavam compras compulsivas e mantinham um comporta- 
mento financeiro adequado para a sobrevivência familiar. Já Pompian e Longo (2004), ao estudarem o público de investidores, constataram que o gênero do indivíduo propiciaram diferentes resultados nos vieses de gestão de investimentos. Para Chen e Volpe (1998), Agarwal et al. (2009); Lusardi e Mitchell (2011), Atkinson e Messy (2012) as mulheres geralmente apresentam menores índices de educação financeira do que os homens; mulheres são menos propensas a responder às perguntas corretamente e mais propensas a dizer que não sabem a resposta de questões financeiras; fazendo um comparativo entre mulheres, as casadas e com renda mais alta possuem melhores niveis de educação financeira em comparação com solteiras e com rendas mais baixas.

Com relação a idade os estudos não são consensuais: Há uma corrente que acredita que indivíduos mais velhos (idade superior a 75 anos) sejam mais tendentes à dívidas por terem aumento de despesas na velhice (BRICKER et al., 2012) e aqueles que revelam as pessoas com menor faixa etária como os mais tendentes à dividas por dependerem de renda familiar e terem comportamentos mais consumistas (KEESE, 2012; TAN, YEN e LOKE, 2011). Os trabalhos de Agarwal et al. (2009), Lusardi e Mitchell (2011), Finke et al. (2011), Atkinson e Messy (2012), Scheresberg (2013) observaram que a idade média de 30 a 40 anos está associada com os maiores índices de letramento financeiro e que a educação financeira é baixa entre os mais jovens e mais velhos; mais velhos têm utilizado empréstimos com altos custos.

Estudos destacam as pessoas com menores faixas de renda como as mais suscetiveis à divida (ZERRENNER, 2007; BRICKER et al., 2012; MARTELO, FAVERO, SOUZA, 2020). Segundo Hastings e Tejeda-Ashton (2013), Atkinson e Messy (2012) baixos níveis de renda estão associados a baixos niveis de educação financeira, sendo que educação financeira e riqueza são conjuntamente determinadas e correlacionadas ao longo do ciclo de vida. Nesse sentido, Zerrenner (2007), Bricker et al. (2012), Lucena et al. (2014), Vieira et al. (2016) advogam que quanto menor o nivel de renda mais financeiramente vulneráveis as pessoas ficam.

Com relação a escolaridade: Kirby et al. (2005) evidenciaram que o baixo letramento financeiro está relacionado com o nivel de escolaridade dos indivíduos. Martelo, Favero e Souza (2020), Chen e Volpe 
(1998), Amadeu (2009), Disney e Gathergood (2011), Lusardi e Mitchell (2011) observam que pessoas com maiores niveis de educação financeira são os que possuem maiores níveis de escolaridade. Gathergood (2012), Vieira et al. (2016) advogam que quanto menor o grau de escolaridade do indivíduo maior é sua tendência a assumir dívidas uma vez que supõe-se que maiores níveis de educação geralmente estão ligados a maiores niveis de letramento financeiro

Quanto a quantidade de dependentes (filhos e agregados), Potrich et al. (2015) apontam maiores niveis de letramento financeiro entre os homens que não possuem dependentes, com um maior nível de escolaridade e com maiores faixas de renda própria e familiar. Conforme Research (2003), Brown e Graf (2013), Martelo, Favero e Souza (2020) solteiros são significativamente mais propensos a ter menores conhecimentos financeiros do que os casados.

Com relação a situação laboral, Chen e Volpe (1998) e Research (2003) discorrem que indivíduos com maior tempo de serviço são mais educados financeiramente em virtude da maior convivência com questões econômicas e financeiras, enquanto que trabalhadores com baixa qualificação ou desempregados apresentam atitudes e comportamentos menos desejáveis. Nesta linha, Gathergood (2012), Vieira et al. (2016) asseveram que as piores condições de trabalho causariam também uma maior propensão ao endividamento e teriam um mais baixo letramento financeiro.

Outros estudos investigaram variáveis socioeconômicas e comportamento materialista como determinantes para o nível de dívidas pessoais. Para compradores compulsivos, a falta de controle e a irresistivel vontade de comprar fazem com que esse processo desempenhe papel central na vida dessas pessoas, levando-as a adquirir os objetos desejados, sem prévio planejamento financeiro, o que os torna mais vulneráveis a divida (RICHINS, 2011). Ainda há aqueles que evidenciam o comportamento financeiro como influenciador da atitude ao endividamento, pois segundo Atkinson e Messy (2012), é o adequado comportamento financeiro que determina um bom planejamento das despesas e a construção da segurança financeira. Para Gathergood (2012) e Vieira et al. (2016) indivíduos solteiros apresentam maior propensão ao materialismo e uso 
irracional de cartão de crédito se comparados aos casados. Segundo Davies e Lea (1995) indivíduos que têm uma atitude favorável aos cartões de crédito têm uma maior probabilidade de possuírem vários cartões e estão mais sujeitos à publicidade. Para Solomon, Bamossy e Askegaard (2002) indivíduos pertencentes a um estrato social mais elevado, acreditam que é mais vantajoso recorrer ao crédito para adquirir bens luxuosos do que aqueles que pertencem a classes médias ou baixas.

Nessa perspectiva, verificou-se a importância de tornar possivel a compreensão das principais diferenças das variáveis socioeconômicas e financeiras pessoais entre as classes A, B e C. Considerando-se que há a possibilidade de um padrão comportamental no que se refere à administração financeira pessoal dentro de uma mesma camada social, o trabalho teve o seguinte objetivo: Verificar se houve diferenças significativas entre as características socioeconômicas e financeiras das pessoas quando separadas por classes sociais.

O presente trabalho se justificou pelo fato de buscar compreender uma temática econômica que tem impacto nas mais diversas áreas sociais, como educação, saúde e cultura. Parte-se do pressuposto que as características socioeconômicas da população influenciam de maneira decisiva na forma com a qual as pessoas fazem a gestão de suas finanças pessoais. Isso é evidenciado pela análise do comportamento das famílias dentro de uma mesma classe social, o que demonstra o quão próximas são as suas decisões financeiras. Karsaklian (2000) discorreu sobre essa ideia ao falar sobre a homogeneidade, dentro dos mesmos estratos sociais, dessas características e a heterogeneidade das mesmas fora deles. Nessa perspectiva, verifica-se a importância de identificar e entender as características socioeconômicas e financeiras populacionais, com o objetivo de tornar possivel a compreensão das principais diferenças destas variáveis entre as classes sociais.

\section{Metodologia}

A presente pesquisa pode ser classificada como descritiva com uso e análise de dados secundários. As variáveis utilizadas foram coletadas da investigação "A trajetória Financeira do Brasileiro" - realizada 
pela AMBIMA - Associação Brasileira das Entidades dos Mercados Financeiro e o Instituto Datafolha, no qual realizaram 2.653 entrevistas em todo o Brasil, abrangendo 130 municípios, durante o mês de junho de 2017. Tal levantamento averiguou quais eram as práticas características socioeconômicas e financeiras das pessoas. Como forma de validação dos dados, houve checagem pessoal amostral (in loco) e também telefônica após a coleta de dados, cobrindo no mínimo $20 \%$ do material que cada pesquisador obteve. A margem de erro ficou em 2 pontos percentuais para mais ou para menos, com nível de confiança de $95 \%$. Os resultados da pesquisa foram divulgados em relatório e em um banco de dados no site da AMBIMA, disponível para acesso e uso a quem se interessasse.

Primeiramente os dados de interesse foram coletados e fez-se um ajuste no banco de dados de forma a verificar as variáveis de interesse da pesquisa (características socioeconômicas e financeiras das pessoas). Tais variáveis foram categorizadas em três grupos, em conformidade com as classes sociais declaradas pelas pessoas: Classe A (junção da A1 e A2 N=134); Classe B (junção da B1 e B2; N=869) e Classe C (junção da $\mathrm{C} 1$ e C2; $\mathrm{N}=1650)$. Não houve resposta de pessoas pertencentes às classes D e E. No estudo de base, para as definições de classes, foi usado o Novo Critério de Classificação Econômica Brasil (CCEB), (KAMAKURA, MAZZON, 2013) determinado como instrumento de segmentação econômica que utiliza o levantamento de características domiciliares (presença e quantidade de alguns itens domiciliares de conforto e grau escolaridade do chefe de família) para diferenciar a população. O critério atribuiu pontos em função de cada característica domiciliar e realizou a soma destes pontos. A seguir, apresenta-se quadro com a definição das variáveis: 
Quadro 1 - Definição operacional das variáveis da pesquisa

\begin{tabular}{|c|c|c|}
\hline Variável & Nome e categoria & Mensuração \\
\hline Nfilhos & $\begin{array}{l}\text { Número de filhos declarados. } \\
\text { (caracteristica socioeconômica). }\end{array}$ & $\begin{array}{l}\text { Contagem. Valores } \\
\text { absolutos. Variável discreta }\end{array}$ \\
\hline RendaF & $\begin{array}{l}\text { Renda Familiar declarada. } \\
\text { (característica socioeconômica). }\end{array}$ & $\begin{array}{l}\text { Escala. } 1 \text { para alta renda (> } \\
20 \text { Salários) a } 7 \text { para baixa } \\
\text { renda (até } 2 \text { Salários). }\end{array}$ \\
\hline Idade & $\begin{array}{l}\text { Idade declarada. } \\
\text { (característica socioeconômica). }\end{array}$ & $\begin{array}{l}\text { Valor absoluto, variável } \\
\text { contínua. }\end{array}$ \\
\hline Trab. & $\begin{array}{l}\text { Situação Laboral declarada. } \\
\text { (característica socioeconômica). }\end{array}$ & $\begin{array}{l}\text { Escala. } 1 \text { para empregos } \\
\text { estáveis a } 10 \text { para } \\
\text { desempregado. }\end{array}$ \\
\hline Estcivil & $\begin{array}{l}\text { Estado Civil Declarado. } \\
\text { (característica socioeconômica). }\end{array}$ & $\begin{array}{l}\text { Variável discreta: 1: Casado } \\
\text { ou com companheiro(a); } 2 \text { : } \\
\text { Solteiro, viuvo, separado, } \\
\text { outro. }\end{array}$ \\
\hline Escola & $\begin{array}{l}\text { Nível de escolaridade declarado } \\
\text { (caracteristica socioeconômica). }\end{array}$ & $\begin{array}{l}\text { Escala. } 1 \text { para } \\
\text { Analfabeto/primário } \\
\text { incompleto a } 8 \text { pós } \\
\text { graduacão completo. }\end{array}$ \\
\hline C.Cred. & $\begin{array}{l}\text { Comportamento declarado com } \\
\text { relação ao uso de cartão de } \\
\text { crédito. } \\
\text { (característica financeira } \\
\text { pessoal). }\end{array}$ & $\begin{array}{l}\text { Escala. } 1 \text { para sem } \\
\text { preocupação com o uso } \\
\text { (consumista) a } 5 \text { uso mais } \\
\text { racional do cartão de } \\
\text { crédito. }\end{array}$ \\
\hline Control. & $\begin{array}{l}\text { Niveis de Controle Financeiro } \\
\text { Pessoal declarado. } \\
\text { (caracteristica financeira } \\
\text { pessoal). }\end{array}$ & $\begin{array}{l}\text { Escala. } 1 \text { para } \\
\text { descontrolado } \\
\text { financeiramente a } 5 \text { muito } \\
\text { controlado financeiramente. }\end{array}$ \\
\hline Mater. & $\begin{array}{l}\text { Comportamento materialista } \\
\text { declarado. (característica } \\
\text { financeira pessoal). }\end{array}$ & $\begin{array}{l}\text { Escala. } 1 \text { para extravagante } \\
\text { a } 7 \text { comedido. }\end{array}$ \\
\hline End. & $\begin{array}{l}\text { Grau de Endividamento pessoal } \\
\text { declarado. (característica } \\
\text { financeira pessoal). }\end{array}$ & $\begin{array}{l}\text { Escala. } 1 \text { para muito } \\
\text { endividado a } 7 \text { para não } \\
\text { endividado. }\end{array}$ \\
\hline
\end{tabular}

Fonte: Elaboração própria

Nenhuma das variáveis acima descritas sofreu alguma modificação e foram consideradas todas as respostas válidas $(\mathrm{N}=2.653)$. $\mathrm{O}$ método de análise empregado foi a estatística descritiva de cada variável por categoria (Classe Social A, B e C) e posteriormente foi feito 
a comparação de médias de cada variável entre grupos usando teste não paramétrico de Kruskal-Wallis (K-W). É usado para comparar duas ou mais amostras independentes de tamanhos iguais ou diferentes. $\mathrm{O}$ equivalente paramétrico do teste de Kruskal-Wallis é o teste F usado na análise de variância de um fator. Um teste de Kruskal-Wallis significante indica que ao menos uma amostra domina estocasticamente uma outra amostra.

Como não se sabia os parâmetros da distribuição dos dados se foram violadas as pressuposições de normalidade e homocedasticidade, optou-se pela não utilização da análise de variância tradicional ANOVA, pois haveria a probabilidade de se obter resultados incorretos. Assim, utilizou-se como teste alternativo não para métrica para a ANOVA o teste de Kruskal-Wallis (K-W) utilizado na comparação de três ou mais grupos de amostras independentes. Indica se há diferença entre pelo menos dois deles. A aplicação do teste utiliza os valores numéricos transformados em postos e agrupados num só conjunto de dados. A comparação dos grupos é realizada por meio da média dos postos (posto médio). Assim, julgou-se o teste K-W adequado aos objetivos do trabalho.

\section{Resultados}

Os resultados da estatística descritiva para os entrevistados da classe A (tabela 1) evidenciaram uma média de 1,15 filhos (46\% não tem filhos, $18 \%$ um filho, $22 \%$ dois filhos, $14 \%$ três filhos ou mais), renda familiar média prevalente de mais de 10 Salários Mínimos, situação laboral considerada mais estável (55 \% são assalariados registrados, aposentados, funcionários públicos ou vivem de rendas; 11 \% são profissionais liberais; $13 \%$ são empresários; 4,47 \% desempregado/procura emprego); 54,4 \% são casados(as) ou com companheiro(a) e com uma escolaridade média prevalente de ensino superior (58\% ensino superior e $26 \%$ ensino médio).

Com relação às variáveis de características financeiras pessoais, observou-se um nível de endividamento médio de 5,51 (baixo) sendo que $42,53 \%$ declararam sem dividas pessoais e apenas 3,7 \% declaram- 
-se super endividados. Quanto ao uso do cartão de crédito, 45,5\% declararam forte concordância de não consumista e 20,14 \% declararam não saberem usar o cartão de crédito e serem consumistas. No quesito controle financeiro pessoal, apresentou média com tendência de uso de ferramentas de controle financeiro pessoal (50\% forte concordância de serem muito controlados financeiramente e 11,94\% declararam ser totalmente descontrolados financeiramente) e quanto ao materialismo, apresentou média com tendência a serem menos extravagantes $(23,88$ $\%$ declararam não ser materialistas, serem mais comedidos e 4,45 \% serem totalmente materialistas).

\section{Tabela 1 - Estatística descritiva das variáveis socioeconômicas e financeiras da Classe A}

\begin{tabular}{|c|c|c|c|c|c|c|c|c|c|c|}
\hline Maxımo & 1 & 1 & I & 19 & 10 & 2 & 5 & 5 & I & 8 \\
\hline Contagem & 134 & 134 & 134 & 134 & 134 & 134 & 134 & 134 & 134 & 134 \\
\hline
\end{tabular}

Fonte: Dados da pesquisa

Para os entrevistados da classe $\mathrm{B}$, a análise descritiva das variáveis de características socioeconômica (tabela 2) relatou uma média de 1,18 filhos (41\% declararam não tem filhos, $23 \%$ um filho e $21 \%$ dois filhos, $15 \%$ três filhos ou mais), renda familiar média prevalente de mais de 3 a 5 Salários Mínimos, situação laboral considerada estável mais prevalente (49 \% são assalariados registrados, aposentados, funcionários públicos e vivem de rendas; $10 \%$ profissionais liberais e 7 \% são empresários; 7,25 \% desempregado/procura emprego); 52,5\% são casados(as) ou com companheiro(a) e com uma escolaridade média prevalente de ensino médio completo ( $45 \%$ ensino médio e $29 \%$ ensino superior).

Com relação às variáveis de características financeiras pessoais (tabela 2), observou-se um baixo nível de endividamento médio sendo que $38,45 \%$ declararam sem dívidas pessoais; $24,7 \%$ com endividamento pessoal baixo e 11,04\% declaram-se super endividados. Quanto ao uso do cartão de crédito, apresentou uma média com tendência mais próxima de não consumista, $(56,85 \%$ forte concordância de não consumista e $11,62 \%$ declararam não saberem usar o cartão de crédito e serem consumistas). No quesito controle financeiro pessoal, apresentou média com tendência de controle financeiro pessoal $(54,32 \%$ forte con- 
cordância de serem muito controlados financeiramente embora 14,04 $\%$ declararam ser totalmente descontrolados financeiramente) e quanto ao materialismo, apresentou média com tendência a serem menos extravagantes $(54,78 \%$ declararam não ser materialistas, serem mais comedidos e 3,80 \% serem totalmente materialistas e fazerem compras por impulso).

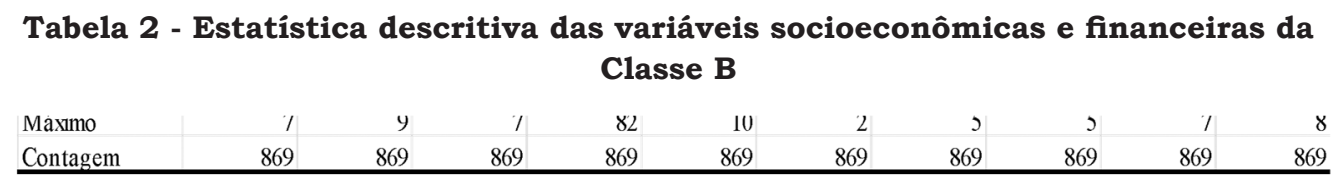

Fonte: Dados da pesquisa

Para os entrevistados da classe $\mathrm{C}$, a análise descritiva das variáveis de características socioeconômica (tabela 3) revelou uma média de 1,49 filhos (35\% declararam não tem filhos, $23 \%$ um filho e $21 \%$ dois filhos, $21 \%$ três filhos ou mais), renda familiar média prevalente de até 2 Salários Mínimos (70,67 \% com renda até 3 salários mínimos), situação laboral instável mais prevalente $(27,21 \%$ declararam ser free lance, bico ou autônomo e 13,27 \% desempregado/procura emprego); 46,90 \% são casados(as) ou com companheiro(a) e com uma escolaridade média prevalente de ensino médio completo $(44,8 \%$ ensino médio e $9,2 \%$ ensino superior).

Com relação às variáveis de características financeiras pessoais (tabela 3), observou-se um baixo nível de endividamento médio sendo que $32,7 \%$ declararam sem dívidas pessoais; $10,8 \%$ com endividamento pessoal baixo e $16 \%$ declararam estarem super endividados. Quanto ao uso do cartão de crédito, apresentou uma média com tendência mais próxima de não consumista, $(59,39$ \% forte concordância de não consumista e 12,6 \% declararam não saberem usar o cartão de crédito e serem consumistas). No quesito controle financeiro pessoal, apresentou média com tendência de controle financeiro pessoal $(48,61 \%$ forte concordância de serem muito controlados financeiramente e $19 \%$ declaram serem totalmente descontrolados) e quanto ao materialismo, apresentou média com tendência a serem menos extravagantes $(55,09$ $\%$ declararam não serem materialistas, mais comedidos e 2,82 \% serem 
totalmente materialistas, fazem compras por impulso).

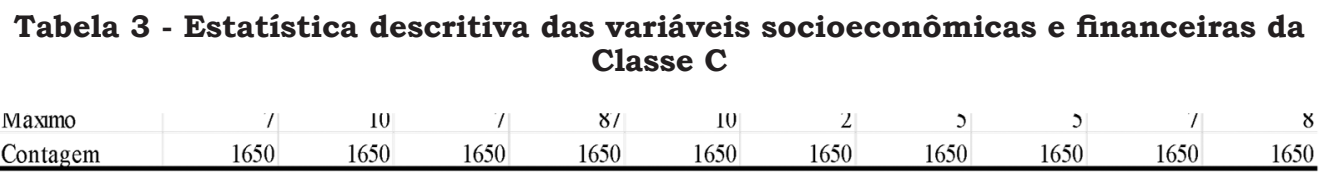

Fonte: Dados da pesquisa

Como relatado na metodologia, foi feito um teste de medias para comparar as variáveis entre os três grupos (Classes sociais) estabelecendo-se as seguintes hipóteses para o teste de Kruskal-Wallis (K-W): $\mathrm{H}_{0}=$ As médias dos grupos são estatisticamente iguais; $\mathrm{H}_{1}=$ As médias dos grupos são estatisticamente diferentes (pelo menos um grupo apresentou média diferente dos demais).

\section{Tabela 4 - Resultado do teste de médias $K-W$ na comparação das variáveis socioe- conômicas e financeiras entre as Classes A, B e C}

Fonte: Dados da pesquisa

Os resultados do teste de média comprovaram que apenas as variáveis Idade (socioeconômica) e Comportamento Materialista (financeira) foram estatisticamente iguais entre os grupos (Classes sociais A, B e C) levando a concluir que as variações observadas foram devidas a variabilidade amostral. Apesar de que as Classes B e C apresentaram uma idade máxima maior e com maiores intervalos, do ponto de vista estatístico pressupõe-se que houve uma homogeneidade em termos de idade entre os grupos (médias próximas de 38 anos com CV próximo de $40 \%$ ). Tal homogeneidade também foi identificada na variável Comportamento Materialista que, apesar de as classes C e B apresentarem resultados nominais que evidenciaram serem mais comedidas ou menos extravagantes em comparação com a Classe $\mathrm{A}$, as variações observadas não foram estatisticamente significativas, sendo, portanto, estatisticamente iguais (médias gerais em torno de 5,28 e CV $32 \%$ ). Assim, as variáveis "Idade" e "Comportamento materialista" não são diferentes em termos 
de classes sociais, conforme o teste de médias. As demais variáveis apresentaram-se estatisticamente diferentes entre os grupos (classes A, B e C) ou seja, em pelo menos dois grupos possuem distribuições de frequência diferentes, médias estatisticamente diferentes, confirmando as análises descritivas.

Esperava-se que o comportamento materialista fosse diferente entre as classes sociais, baseando-se nos estudos de Cohen e Cohen (1996) e Chaplin et al. (2014). A constatação de que o comportamento materialista foi igual entre as classes sociais nos dados da pesquisa corroborou os resultados de Nascimento, Abreu e Nascimento (2017) no qual identificaram que o antecedente "classe social" não influencia o nivel de materialismo das pessoas. Resultados foram condizentes com estudo correlato nacional.

Os resultados da pesquisa validaram o pressuposto que características socioeconômicas possuem relação com as características financeiras pessoais corroborando os estudos anteriores (POMPIAN, LONGO, 2004; KIRBY et al. 2005). Comprovou-se que o fator financeiro pessoal foi uma das características na definição das classes sociais, sendo que as variáveis número de filhos, renda familiar, situação laboral, estado civil, escolaridade, uso do cartão de crédito, uso de controles financeiros pessoais e niveis de endividamento pessoal foram estatisticamente diferentes entre as classes sociais.

Os resultados demonstraram que a variável número de filhos foi estatisticamente diferente entre os grupos (Classes Sociais). A Classe A apresentou a menor média de filhos evidenciada pelo o maior percentual de famílias que não tem filhos bem como menores percentuais de 1 ou mais filhos e Classe $\mathrm{C}$ com a maior média de filhos maiores percentuais de maior numero de filhos.

Quanto à Renda Familiar, apresentou-se também estatisticamente diferente a 0,01. Como era de se esperar, por ser uma variável discriminante da própria classificação em extratos sociais, a Classe $\mathrm{C}$ apresentou menores médias de renda familiar enquanto a Classe A apresentou média de maiores rendas, sendo as distribuições consideradas heterogêneas uma vez que o critério de classificação social é a renda familiar per capta. 
A situação laboral apresentou diferenças significativas, sendo consideradas condições de trabalho mais estáveis nas Classes A e B, maior número de empregados formais nestas classes. A Classe $\mathrm{C}$ apresentou o maior número de pessoas com trabalhos informais e condições de emprego instáveis e também o maior número de pessoas desempregadas ou que estão a procura de emprego/trabalho.

Foram observadas diferenças significativas também na variável estado civil na qual as maiores médias de casados(as) ou com companheiro(a) foram observados na Classe $\mathrm{A}$ e as menores na Classe $\mathrm{C}$ que apresentou o maior percentual de pessoas separadas, divorciadas, viúvas ou em outras condições.

Também a variável Escolaridade foi diferente entre os grupos. A Classe A apresentou escolaridade média prevalente de ensino superior e menores percentuais das outras escolaridades. As classes B e C apresentaram escolaridade média prevalente de ensino médio completo sendo que a classe $\mathrm{C}$ apresentou maior percentual de pessoas com baixa formação escolar e menor percentual de formação de ensino superior em comparação com as demais classes. Isto já era de se esperar uma vez que um dos critérios para separação em classes sociais é também a escolaridade.

A variável que mediu o nível de endividamento pessoal declarado apresentou-se também estatisticamente diferente entre os grupos. Na Classe A houve o maior percentual de pessoas sem dividas e de pessoas com baixo endividamento e o menor percentual de super endividados, embora ainda apresente pessoas nesta situação, em comparação com os outros grupos. Por outro lado, a classe C apresentou menor percentual de pessoas sem dívidas e de pessoas ou com baixo endividamento e maior percentual de pessoas super endividadas em comparação com os outros grupos.

A variável Uso de cartão de crédito também apresentou-se diferente entre os grupos. A Classe $\mathrm{C}$ apresentou o maior percentual de pessoas com forte tendência de não ser consumista. Classe B apresentou o menor percentual de pessoas que declararam não saber usar o cartão de crédito e maior concordância em não ser consumista. A classe 
LEITE FILHO, G. A. Características socioeconômicas e financeiras pessoais...

A apresentou maiores percentuais de pessoas que se declararam consumistas e não saberem usar corretamente o cartão de credito.

A variável Controle financeiro apresentou-se diferente entre os grupos. A classe B apresentou-se como mais controlada financeiramente seguida pela classe A. Os menores percentuais de controle financeiro e maiores de descontrole foram observados na Classe C.

\section{Discussão}

As classes sociais A e B apresentaram menor número de agregados familiares em comparação com a classe $\mathrm{C}$, corroborando os resultados do o relatório Situação da População Mundial da ONU (dados do Brasil), no qual conclui que a parcela mais rica da população, que corresponde a $20 \%$ dos brasileiros, apresenta a menor taxa de fecundidade, com índice médio de 0,77 filho por mulher. Já os $20 \%$ mais pobres aparecem como os que mais têm filhos, são 2,9 por mulher. Além disso, mulheres com mais oportunidades financeiras e educacionais durante a vida (Classes Sociais mais altas) apresentam menor taxa de fecundidade, enquanto as mais pobres ficam grávidas mais vezes e mais novas, em média (ONU, 2018). Menores agregados familiares possibitariam melhores condições de estudo e trabalho e, consequentemente, melhores situações financeiras.

Do ponto de vista financeiro, segundo Lea et al. (1993), Godwin (1998), Keese (2010) a situação das classes quando maior é o agregado familiar, mais necessidades existem para satisfazer, logo maior é a probabilidade de existir uma situação de penúria financeira e endividamento que é o caso dos resultados para a Classe C (mais filhos, piores condições de trabalho e maiores níveis de endividamento). Os autores ainda observam que pessoas que ainda não constituíram uma família ou que vivem sozinhas, tendem a menor propensão ao endividamento, tendo em vista que não possuem compromisso exclusivo com a família (caso dos resultados da Classe A, menor agregado familiar, melhores empregos, maior renda e menor endividamento).

Supõe-se que niveis de rendas mais baixas na Classe $\mathrm{C}$ a tornam mais vulnerável financeiramente, aliado a baixa escolaridade, piores 
empregos e maior agregado familiar geram necessidades financeiras. Tal suposição encontra respaldo nos trabalhos de Zerrenner (2007), Bricker et al. (2012), Lucena et al. (2014), Vieira et al. (2016) onde advogam que quanto menor o nivel de renda mais financeiramente vulneráveis as pessoas ficam. Santos e Souza (2014) concluíram que as pessoas de rendas mais baixas são mais propensas ao endividamento o que validou as diferenças dos resultados para a Classe $\mathrm{C}$ em comparação com as classes A e B.

Os resultados legitimaram as assertivas teóricas que destacam as pessoas com menores faixas de renda como as mais suscetiveis à dividas e menos letradas financeiramente (ZERRENNER, 2007; BRICKER et al., 2012; MARTELO, FAVERO, SOUZA, 2020). Segundo Hastings e Tejeda-Ashton (2013), Atkinson e Messy (2012) pessoas com menores níveis de renda estão associadas a baixos níveis de educação financeira, sendo que educação financeira e riqueza conjuntamente determinadas e correlacionadas ao longo do ciclo de vida. Nesse sentido, Zerrenner (2007), Bricker et al. (2012), Lucena et al. (2014), Vieira et al. (2016) advogam que quanto menor o nível de renda mais financeiramente vulneráveis as pessoas ficam.

Fazendo ligação com as variáveis "situação laboral, escolaridade, número de filhos" o relatório da ONU (2018) assevera que quando uma família tem o poder e os meios para prevenir ou adiar uma gravidez, por exemplo, ela tem mais controle sobre sua saúde, pode ter mais anos de escolaridade, consequentemente melhores empregos, pode ingressar ou se manter no mercado de trabalho remunerado e realizar por completo seu potencial econômico. Assim, terem maiores níveis de renda o que confirma esta característica verificada nas classes sociais mais elevadas.

Consequentemente, do ponto de vista laboral, os melhores empregos ficam com as pessoas da classe A. Segundo Araujo (2003), as famílias de classe pobre (Classe C) se apresentam como mais excluídas da participação nos bens e serviços oferecidos pelo Estado, embora seja a mais necessitada. Organizam-se em torno da figura feminina e é centrado na figura dos filhos. Do ponto de vista financeiro, Gathergood (2012) assevera que as piores condições de trabalho causariam também uma 
maior propensão ao endividamento, características estas observadas na Classe C. Chen e Volpe (1998) e Research (2003) discorrem que indivíduos com maior tempo de serviço são mais educados financeiramente em virtude da maior convivência com questões econômicas e financeiras, enquanto que trabalhadores com baixa qualificação ou desempregados apresentam atitudes e comportamentos menos desejáveis.

Nesse sentido, Bonadia (2008) argumenta que a educação é um dos fatores determinantes das condições de trabalho. Aqueles que possuem um nivel maior de estudo poderão ocupar-se em atividades cada vez mais reconhecidas monetariamente, corroborando os resultados da Classe A (melhor situação laboral e maior renda). Segundo o autor, a classe social, estado onde reside, seu sexo, idade e raça também serão fatores decisórios para seu salário e para o seu nível educacional.

Os resultados evidenciaram que os niveis de escolaridades foram estatisticamente diferentes entre os grupos denotando que houve um maior letramento financeiro nas classes mais altas (A e B). Tais resultados validam as assertivas de Kirby et al. (2005) no qual defendem que o baixo letramento financeiro está relacionado com o nível de escolaridade dos indivíduos. Nesse sentido, estudos de Martelo, Favero e Souza (2020), Chen e Volpe (1998), Amadeu (2009), Disney e Gathergood (2011), Lusardi e Mitchell (2011) observaram que pessoas com maiores níveis de educação financeira são os que possuem maiores níveis de escolaridade sendo que aqueles com menor nível educacional são menos propensos a responder às perguntas corretamente e mais propensos a dizer que não sabem a resposta. Gathergood (2012) ainda observa que quanto menor o grau de escolaridade do indivíduo maior é sua tendência a assumir dívidas e ter descontrole financeiro uma vez que supõe-se que maiores níveis de educação geralmente estão ligados a maiores níveis de letramento financeiro.

Santos e Ribeiro (2016) discutiram estratificação e desigualdade. Concluíram que a estratificação social é considerada como explicativo-chave das mudanças recentes na distribuição de renda no Brasil. Destaca-se o papel das divisões de classe ao nível da estrutura do emprego, ao qual se agregam grupos de status, fatores de segmentação e credenciais educacionais ou seja, melhores e mais remunerados empregos 
estão nas classes mais altas, o que confirma os resultados da presente pesquisa.

Segundo Soares (2002), em um estudo sobre educação, pobreza e desigualdade no Brasil concluiu que o nivel de renda do indivíduo é formado pela educação e as diferenças de nível de renda já existentes na sociedade são reproduzidas pelo nível de escolaridade dos indivíduos. Assim, validaram os resultados da pesquisa no qual a escolaridade foi diferente entre as classes sendo as mais ricas, mais letradas e com melhor situação laboral. As implicações do ponto de vista financeiro é que aqueles com maiores niveis de escolaridade, renda e melhores condições de trabalho tendem a assumir menores dividas, argumento este suportado por Gathergood (2012), Vieira et al. (2016) no qual advogam que quanto menor o grau de escolaridade do indivíduo maior é sua tendência a assumir dividas uma vez que supõe-se que maiores níveis de educação geralmente estão ligados a maiores níveis de letramento financeiro. Assim, a medida que decai na classe social, maior é o nível de endividamento das pessoas o que pode ser explicado talvez pelo mesmo comportamento da renda familiar que segue a mesma tendência. Talvez estes resultados possam estar ligados também a quantidade de filhos. As pessoas das classes B e C por terem piores empregos, menores rendas e maiores agregados familiares precisam recorrer a modalidades de empréstimos para o custeio da casa.

Para além disso, outra explicação para o maior endividamento da Classe $\mathrm{C}$, além da renda mais baixa, pode estar no trabalho de Alves et al. (2013) no qual discutem que a escolaridade mais baixa da Classe C, tal como dificuldades na leitura, compreensão e interpretação de termos como juros, inflação, cheque especial e empréstimo pessoal, e suas implicações práticas na vida financeira familiar podem se constituir em fatores que influenciam o nivel de endividamento. Parte-se do pressuposto que as classes mais escolarizadas (A e B) já teriam nivel de letramento financeiro que permitem compreender e interpretar tais termos.

Observa-se ainda que os consumidores de classes sociais inferiores são menos informados sobre o preço e mais sujeitos a comprar produtos em promoção e a prazo. Ao contrário, os membros das classes sociais mais privilegiadas utilizam menos os preços como referência e 
sim o valor intrínseco dos produtos (WENGRZYNEK, CARMO, 2003)

Apesar de serem menos letradas disto, os resultados evidenciaram que as pessoas das Classes B e C usariam o cartão de crédito para as necessidades básicas, sendo assim menos consumistas do que as pessoas da Classe A, fator este talvez imposto pela limitação da renda. Fazendo uma ligação com os resultados do endividamento, talvez os maiores percentuais de endividamento nas classes C e B estão não ligados ao uso materialista do cartão de crédito mas sim ao uso de modalidades de crédito (cartão, empréstimos e financiamentos) como renda complementar para a própria sobrevivência ou compra de bens ou pagamento de despesas familiares considerados necessários. Tal assertiva corrobora o trabalho de Sciré (2009) no qual a autora explana que em classes mais baixas como o manejo dos cartões tornou-se crucial na gestão do orçamento doméstico ao mesmo tempo em que a renda (não só presente, mas também futura) advinda do mesmo encontra-se totalmente comprometida com as obrigações assumidas no supermercado.

A classe A, embora mais letrada, mostrou-se mais consumista e menos racional no uso da modalidade de cartão de crédito em comparação com as demais. Embora da teoria da aprendizagem tem-se que, devido à baixa renda, os adolescentes de classe social mais baixa têm menos experiências com dinheiro e podem ser menos cientes de alguns aspectos de consumo do que adolescentes de classe social mais alta (WARD, 1974). Sugere que os jovens de classe social mais alta têm maior preferência a determinadas marcas e têm maior tendência a buscar mais informações antes da tomada de decisão. Contudo, tais teorias foram refutadas, pois o comportamento materialista foi estatisticamente igual entre os grupos (Classes).

A classe A mostrou-se mais consumista e menos racional no uso da modalidade de cartão de crédito em comparação com as demais. Para Gathergood, (2012) indivíduos solteiros apresentam maior propensão ao materialismo e uso irracional de cartão de crédito se comparados aos casados, característica da classe A. Supõe-se que maiores níveis de renda fazem as pessoas usarem mais o cartão de crédito. Raaij e Gianotten(1990) observaram que pessoas com rendimentos mais elevados tiveram uma maior propensão para usar cartões de crédito. Davies e Lea, 
(1995) indivíduos que têm uma atitude favorável aos cartões de crédito têm uma maior probabilidade de possuírem vários cartões e estão mais sujeitos à publicidade. Para Solomon, Bamossye Askegaard (2002) indivíduos pertencentes a um estrato social mais elevado, acreditam que é mais vantajoso recorrer ao crédito para adquirir bens luxuosos do que aqueles que pertencem a classes médias ou baixas que usam o crédito para suas necessidades mais elementares.

\section{Conclusão}

O objetivo do trabalho foi verificar se houve diferenças significativas entre as características socioeconômicas e financeiras das pessoas quando separadas por classes sociais. Os resultados do estudo levaram a concluir pela comprovação das teorias e validação de estudos anteriores que variáveis financeiras pessoais foram determinantes na definição das classes sociais, sendo que os atributos "número de filhos, renda familiar, situação laboral, estado civil, escolaridade, uso do cartão de crédito, uso de controles financeiros pessoais e niveis de endividamento pessoal" foram estatisticamente diferentes entre as classes sociais. As variáveis "Idade e Comportamento Materialista" foram estatisticamente iguais entre os grupos.

Concluiu-se que a Classe A apresentou a menor média de filhos e a Classe C maior média de filhos. Quanto à Renda Familiar, a Classe $\mathrm{C}$ apresentou menores médias de renda familiar enquanto a Classe A apresentou maior renda. Verificou-se condições de trabalho mais estáveis nas Classes $\mathrm{A}$ e $\mathrm{B}$, enquanto a Classe $\mathrm{C}$ apresentou o maior número de pessoas com trabalhos informais e condições de emprego instáveis e também o maior número de pessoas desempregadas. As maiores médias de casados(as) ou com companheiro(a) foram observados na Classe A e as menores na Classe $\mathrm{C}$ que apresentou o maior percentual de pessoas separadas, divorciadas, viúvas ou em outras condições. Concluiu-se ainda que a Classe A apresentou maior escolaridade e maior letramento financeiro. Com relação aos niveis de endividamento, concluiu-se que na classe A houve o maior percentual de pessoas sem dividas e de pessoas com baixo endividamento enquanto na classe $\mathrm{C}$ apresentou maior percentual de pessoas super endividadas. 
Concluiu-se ainda que a Classe $\mathrm{C}$ apresentou o maior percentual de pessoas com forte tendência de não ser consumista enquanto na classe A apresentou maiores percentuais de pessoas que se declararam consumistas e não saberem usar corretamente o cartão de credito. Com relação ao controle financeiro pessoal, a classe B apresentou-se como mais controlada financeiramente seguida pela classe A. Os menores percentuais de controle financeiro e maiores descontrole foram observados na Classe C.

Como pesquisas futuras, sugere-se continuar os estudos de comparação de letramento financeiro e atitudes financeiras das classes sociais bem como tentar estudar quais são os seus fatores determinantes.

\section{Referências}

AGARWAL, S.; DRISCOLL, J.; GABAIX, X.; LAIBSON, D. The age of reason: financial decisions over the lifecycle with implications for regulation. Brookings Papers on Economic Activity Fall, p. 51-101, 2009.

ALVES, G. L. C.; STUCCHI, B. de O.; MAHMOUD, R.; NASCIMENTO, B.; SAMPAIO, Y.; BACHA, M. de L.. Baixa renda: endividamento e compreensão de notícias econômicas. Inovcom, Vol 5, n. 2, pp. 38-51, 2013

AMADEU, J. R. A educação financeira e sua influência nas decisões de consumo e investimento: proposta de inserção da disciplina na matriz curricular. 91 f. Dissertação (Mestrado em Educação) - Universidade do Oeste Paulista, São Paulo, 2009.

ARAUJO, W. da R. Representações sociais sobre família e classes sociais. 113 f. Dissertação (Mestrado em Serviço Social) - Universidade Federal de Pernambuco, Recife, 2003.

ATKINSON, A.; MESSY, F. Measuring financial literacy: results of the OECD / International Network on Financial Education (INFE) pilot study, 2012. Disponível: http://dx.doi.org/10.1787/5k9csfs90fr4-en

BERG, C. J.; SANEM, J. R.; LUST, K. A.; AHLUWALIA, J. S.; KIRCH. M. A. Health-related characteristics and incurring credit card debt as problem behaviors among college students. The Internet Journal of Mental Health, 6, (2), pp.1-9, 2010. 
BONADIA, P. R. A Relação Entre o Nivel de Escolaridade e a Renda no Brasil. 25 f. Monografia de Conclusão de Curso (Economia) - IBMEC, São Paulo, 2008.

BRICKER, J.; KENNICKELL, A. B.; MOORE, K. B.; SABELHAUS, J Changes in U.S. family finances from 2007 to 2010: evidence from the Survey of Consumer Finances. Federal reserve Bulletin, 98, (2), pp.1-80, 2012.

BROWN, M.; GRAF, R. Financial literacy and retirement planning in Switzerland. Numeracy, v. 6, n. 2, art. 6, 2013.

CAMPARA, J. P.; VIEIRA, K. M.; CERETTA, P. S. Entendendo a atitude ao endividamento: fatores comportamentais e variáveis socioeconômicas o determinam? Revista Eletrônica de Ciência Administrativa, 15, (1), pp. 5-24, 2016.

CHAPLIN, L.N.; HILL, R.P.; JOHN, D.R. 2014. Poverty and materialism: A look at impoverished versus affluent children. Journal of Public Policy \& Marketing, 33,(1), pp.78-92, 2014.

CHEN, H.; VOLPE, R. P. An analysis of personal financial literacy among college students. Financial Services Review, v. 7, n. 2, p. 107-128, 1998.

COHEN, P.; COHEN, J. Life values and adolescents mental health. Mahwah, Lawrence Erlbaun, 196 p, 1996.

DAVIES, E.; LEA, E. G. Student attitudes to student debt. Journal of Economic Psychology, vol. 16, issue 4, 663-679, 1995.

DISNEY, R.; GATHERGOOD, J. Financial literacy and indebtedness: new evidence for UK consumers. In: Econ Papers, 2011.

FINKE, M. S.; HOWE, J. S.; HUSTON, S. J. Old Age and the Decline in Financial Literacy. Social Science Research Network Working Paper, 2011. Disponivel em: < http://www.tilkingroup.com/texastech.pdf>. Acesso em: 23 jan. 2021.

GATHERGOOD, J. Self-Control, Financial Literacy and Consumer OverIndebtedness. Journal of Economic Psychology, 33, (3), 2012.

HASTINGS, J.; TEJEDA-ASHTON, L. Financial literacy, information, and demand elasticity: Survey and experimental evidence from Mexico. NBER Working Paper 14538. 2008. Disponível em: < http://www.nber. 
org/papers/w14538.pdf?new_window=1>. Acesso em: 22 dez, 2013.

HUANG, J.; KISGEN, D. J. Gender and Corporate Finance: Are Male Executives Overconfident Relative to Female Executives? Journal of Financial Economics, 180,(3), pp.822-839, 2013.

KAMAKURA, W.; MAZZON, J. A. Critérios de estratificação e comparação de classificadores socioeconômicos no Brasil. Revista de Administração de Empresas. vol.56 no.1 São Paulo Jan./Feb. 2016

KARSAKLIAN, E. Comportamento do Consumidor. São Paulo: Atlas, 2000. 303p.

KEESE, M. Who Feels Constrained by High Debt Burdens? - Subjective vs. Objective Measures of Household Indebtedness. Journal of Economic Psychology, 33,(169), pp.5-31. 2012.

KIRBY, K. N.; WINSTON, G. C.; SANTIESTEBAN, M. Impatience and grades: delay-discount rates correlate negatively with college GPA. Learning and Individual Differences, 15, (3), pp. 213-222, 2005.

LUCENA, W. G.; SANTOS, J.; ASSIS, J.; SANTOS, M. Fatores que influenciam o endividamento e a inadimplência no setor imobiliário da cidade de Toritama-pe à luz das finanças comportamentais. Holos, 6, $10,2014$.

LUSARDI, A.; MITCHELL, O. S. Financial literacy and retirement planning in the United States. Journal of Pension Economics and Finance, 10, 4, pp. 509-525, 2011.

MARTELO, J. R.; FAVERO, E.; SOUZA, W. D. de. Personalidade e decisão financeira: um estudo com jovens do Exército Brasileiro. Revista de Contabilidade e Organizações, vol. 14, e166547, 2020.

MULLER, K. O. Sociedade de consumo e cultura do endividamento: estudo de caso sobre compradores compulsivos em Porto Alegre. Trabalho de conclusão de curso. Universidade Federal do Rio Grande do Sul, Porto Alegre, 2010.

ORGANIZAÇÃO DAS NAÇÕES UNIDAS - ONU. Situação da População Mundial 2018 - O Poder de Escolha: Direitos reprodutivos e a transição demográfica. Disponivel em: https://brazil.unfpa.org/pt-br/news/ situacao-da-populacao-mundial-2018. Acesso em 21/06/2021. 
POMPIAN, M. M.; LONGO, J. M. A new paradigm for practical application of behavioral finance: creating investment programs based on personality type and gender to produce better investment outcomes. The Journal of Wealth Management, 7,(2), pp. 9-15. 2004.

POTRICH, A. C. G.; VIEIRA, K. M.; CAMPARA, J. P.; SANTOS, L. F. D. O. Educação Financeira dos Gaúchos: Proposição de uma Medida e Relação com as Variáveis Socioeconômicas e Demográficas. Sociedade, Contabilidade e Gestão, 9, (3), p. 109-129, 2015.

RESEARCH, R. M. ANZ survey of adult financial literacy in Australia, 2003.Disponível em: https://www.anz.com/resources/3/1/31cbc1fd9491-4a22-91dc-4c803e4c34ab/adult-financial-literacy-survey-fullresults.pdf. Acesso em: 20/05/2021.

RICHINS, M. L. Materialism, transformation expectations, and spending: implications for credit use. Journal of Public Policy \& Marketing, 30, (2), pp. 141-156, 2011.

SANTOS, J. A. F.; RIBEIRO, L. V. F. Emprego, estratificação e desigualdade. Mercado de trabalho, Estudos Avançados. 30, 87, MayAug 2016.

SCHERESBERG, C. B. Financial literacy and financial behavior among young adults: Evidence and implications. Numeracy, v. 6, n. 2, art. 5, 2013.

SOARES, S. Desigualdade, Educação e Pobreza no Brasil. São Paulo: IPEA, 2002.

SOLOMON, M. R.; BAMOSSY, G.; ASKEGAARD, S. Consumer behaviour: A European perspective. Financial Times/Prentice Hall, cop. 2002.

TAN, A. K. G.; YEN, S.; LOKE, Y. J. Credit card holders, convenience users and revolvers: a tobit model with binary selection and ordinal treatment. Journal of Applied Economics, 14, (2), pp. 225- 255, 2011.

VIEIRA, K. M.; FRAGA, L. D. S.; VALCANOVER, V. M.; CATTELAN, V. D.; FLORES, S. A. M.; CAMPARA, J. P. De Onde Vem o Bem-Estar Financeiro?: Análise dos Fatores Comportamentais, do Gerenciamento Financeiro e da Renda. Teoria e Prática em Administração, v. 6, n. 2, p. 136-171, 2016.

WARD, S. Consumer socialization. Journal of Consumer Research, v. 1, p. 1-14, Sept. 1974. 